\title{
Knee meniscus suturing techniques in children and indications for their use
}

\author{
D.D. Pavlova ${ }^{1}$, S.M. Sharkov ${ }^{1,2}$, M.A. Petrov ${ }^{3}$ \\ 'Mozorov Children's Clinical Hospital, Moscow, Russian Federation \\ ${ }^{2}$ Sechenov First Moscow State Medical University, Moscow, Russian Federation \\ ${ }^{3}$ Pirogov Russian National Research Medical University, Moscow, Russian Federation
}

\begin{abstract}
Relevance The problem of meniscus injuries in children has acquired a particular relevance. The growth in their incidence has been caused not only by an active sports- and lifestyle of pediatric patients but also by improved diagnosis due to magnetic resonance and arthroscopic techniques. Aim To formulate indications for the use of various methods of meniscus suturing in children and to evaluate the results of treatment of meniscus injuries in children, depending on the location of the tears. Materials and methods Our study included 74 patients who underwent meniscus suturing from March 2018 to December 2020. The age of the children ranged from 10 to 17 years. Time since the injury ranged from one day to 3 years. Before surgery, they underwent instrumental examination; knee joint radiography was performed in all patients, knee MRI was performed in 66 patients. Results Meniscus sutures were evaluated clinically and instrumentally at 6 months after the operation (MRI). One year after the meniscus repair, X-rays of the knee were taken to assess osteoarthritis. There was no pain after surgery in 68 children $(91.9 \%)$. There were no blocks of the knee joint after surgery in all children. Full recovery of the range of motion in the knee joint was observed in 69 children (93.2 \%). Complications were noted in five children. Conclusion Poor results after meniscectomy has led to the emergence of several methods that allow meniscus repair and avoid meniscectomy that impairs knee functions. In children, the potential for restoration of menisci after their reconstruction is higher than in adults. It is possible to repair lesions not only in the white zone but after periods of more than three months since the injury. The choice of the meniscus suture technique used is determined by the location of the tear, taking into account possible complications. The use of a combination of methods allows reconstruction of the damaged meniscus regardless of the location of the tear and the complexity of the injury. Good clinical results, absence of complaints and return to usual physical activities in the immediate postoperative period should be regarded as positive outcomes subjected to further study.
\end{abstract}

Keywords: meniscus, children, meniscus suture, "inside-out", "outside-into", "all inside"

\section{INTRODUCTION}

Isolated traumatic meniscus injuries are more common in the pediatric population than in adults [1]. According to different reports, the incidence of meniscus injuries in children varies from 0.15 to $36.7 \%$ of all knee injuries [2,3]. Injuries simultaneously to two menisci of one knee joint and their combination with damage to other structures such as hyaline cartilage $(42.6 \%$ for the medial meniscus, $31.1 \%$ for the lateral meniscus), anterior cruciate ligament ( $24 \%$ for the medial meniscus, $28,3 \%$ for the lateral meniscus), medial patellar plica (16\% for the medial meniscus, $14.6 \%$ for the lateral meniscus) are possible [2]. Damage to the posterior root of the meniscus occurs in every sixth child with meniscus lesions [4].

Two main methods of treatment in injuries of knee joint meniscus have been described: meniscectomy and meniscus suturing [5]. There are a large number of publications that have shown the relationship between removal of the meniscus and the development of osteoarthritis in adults [6-9]. Convincing evidence has also been described that full or partial meniscectomy is a detrimental procedure in children, as the consequence of such treatment is the development of early osteoarthritis $[10,11]$.

In the pediatric group of patients, the success rate of the meniscus suturing is higher than in adults [12]. This is due to the peculiarities of the histological structure of the menisci in children. The formations that perform the function of "feeding channels", delivering nutrients from the synovial fluid into the thickness of the meniscus, and the microvessels reaching the internal third of the meniscus in children, allow suturing the menisci in the white zone [13]. Modern trends in the treatment of meniscus injuries are to restore the damaged segment of the meniscus with meniscus suturing which is performed using various techniques and their combinations [14].

Purpose To formulate indications for the use of various methods of meniscus suturing in children and to evaluate the results of treatment of meniscus injuries in children, depending on the location of the tears.

\section{MATERIAL AND METHODS}

Our study included 74 patients who underwent meniscus suturing from March 2018 to December 2019 (Table 1). The inclusion criteria for the study were unstable meniscus tear, absence of pronounced degenerative changes, and the observation period of patients at least 12 months from the date of surgery. The exclusion criteria were cases of simultaneous resection and suture of the meniscus in one knee joint (except for children with discoid menisci), the follow-up period less than 12 months from the date of surgery, and the absence of data from control instrumental studies. This study was carried out in compliance with the Declaration of 
Helsinki of the World Medical Association "Ethical Principles for Medical Research Involving Human Subjects" as amended in 2000.

Table 1

Injuries treated with meniscus suturing

\begin{tabular}{|l|c|}
\hline \multicolumn{1}{|c|}{ Injured structure } & Number of children \\
\hline Lateral meniscus & 28 \\
\hline Medial meniscus & 24 \\
\hline Both menisci & 14 \\
\hline Discoid meniscus & 8 \\
\hline Total & 74 \\
\hline
\end{tabular}

The age of the children ranged from 10 to 17 years (mean age, 13.5 years). Time since the injury was from one day to 3 years. Table 1 shows the structure of the lesions in which the meniscus suture was performed. In 8 patients, damage to the discoid meniscus was revealed: the altered part was removed, and the remaining one was fixed. In 18 patients, meniscus injury was combined with anterior cruciate ligament tear. If the rupture was of a small length $(2-3 \mathrm{~cm})$, the patients had meniscus suturing and simultaneous reconstruction of the ACL. In case of extended ruptures (more than $3 \mathrm{~cm}$ ) or damage to both menisci, the meniscus or menisci were reconstructed first, and the ACL plasty followed after 4-8 weeks.

Before surgery, all patients underwent instrumental diagnosis in addition to physical examination. Radiographic examination of the knee joint was performed in all patients (X-rays of the knee joint in two projections or computed tomography in order to carry out differential diagnosis with other pathologies of the knee joint, to identify signs of osteoarthritis and indirect radiological signs of the presence of a discoid meniscus). Knee MRI was performed in 66 patients. In some children, a meniscus tear was an intraoperative finding (Fig. 1, 2).

We identified horizontal, vertical, radial tears, tears like "bucket handle" and "parrot beak", ruptures of the ramp and the root of the medial meniscus, as well as combined tears (Table 2) [15]. In our practice, we did not take into account the time since the moment of injury as an indication or contraindication for performing meniscus stitching.

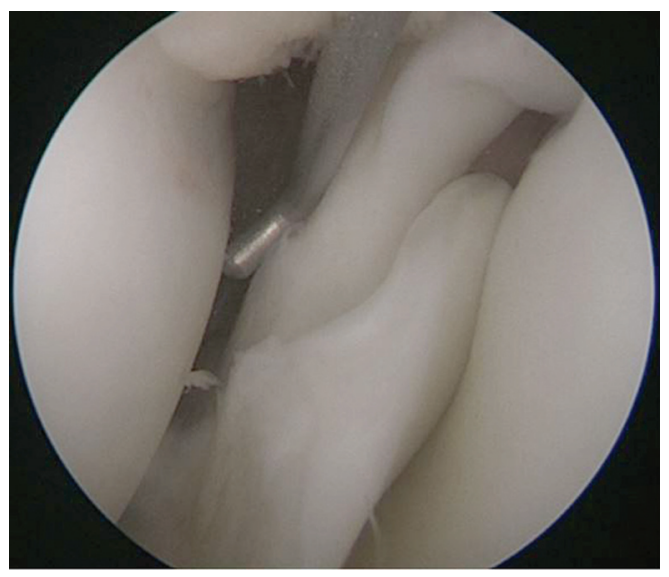

Fig. 1 Flap-like tear of the lateral meniscus body

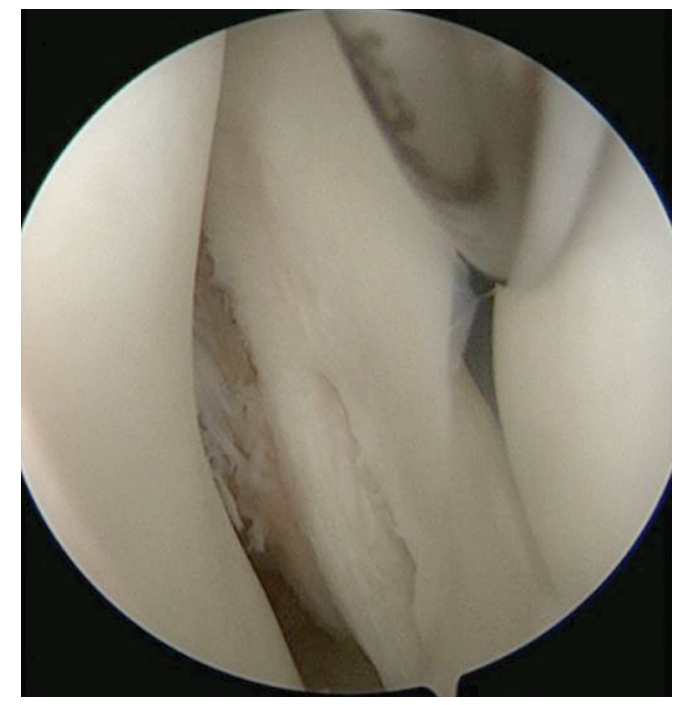

Fig. 2 Vertical tears of the posterior horn of the lateral meniscus

Table 2

Types of meniscus tears

\begin{tabular}{|l|c|}
\hline \multicolumn{1}{|c|}{ Types of meniscus tear } & Number \\
\hline Horizontal tear & 6 \\
\hline Vertical tear & 37 \\
\hline Radial tear & 2 \\
\hline Bucket-handle tear & 14 \\
\hline Parrot-beak tear & 2 \\
\hline Meniscus ramp tear & 1 \\
\hline $\begin{array}{l}\text { Tear of the posterior root of the medial } \\
\text { meniscus }\end{array}$ & 1 \\
\hline Complex tears & 11 \\
\hline Total & 74 \\
\hline
\end{tabular}

The following techniques were used for reconstructing the meniscus: "outside to inside", "inside to outside" and "all inside", as well as their combinations for multiplanar and extended tears (Table 3). To reconstruct the tear of the posterior root of the medial meniscus, the latter was re-fixed with cortical fixation on the anterior surface of the tibia. The choice of the meniscus reconstruction method was determined by the location of the tear and its complexity.

In buckle-handle and parrot-beak types of injuries, a combination of several meniscus suture technologies was performed. The rehabilitation period did not depend on the type of techniques used.

Methods of descriptive statistics were used to process the data. The McNemar test $(p<0.001)$ was used to compare populations for qualitative characteristics.

\section{Meniscus suturing techniques}

The choice of the meniscus reconstruction method is determined by the location of the damage and its complexity, which are the length and multidirectional line of the tear. Several tear lines at the same level are also possible. We analyzed the technical features of the existing meniscus suture techniques and possible complications after their use and made a scheme that allows us to select the most appropriate meniscus suture technique for a particular location of the tear (Table 3). 
Meniscus suture techniques and indications for their use in regard to tear location

\begin{tabular}{|l|c|c|c|}
\hline \multirow{2}{*}{} & \multicolumn{3}{|c|}{ Suture technique } \\
\cline { 2 - 4 } & Outside-in & Inside-out & All inside \\
\hline Anterior horn of the medial meniscus & Convenient, safe & Inconvenient, safe & Inconvenient, safe \\
\hline Anterior horn of the lateral meniscus & Convenient, safe & Inconvenient, safe & Inconvenient, safe \\
\hline Medial meniscus body & Convenient, safe & Convenient, safe & Convenient, safe \\
\hline Lateral meniscus body & Inconvenient, safe & Convenient, safe & Convenient, safe \\
\hline Posterior horn of the medial meniscus & Inconvenient, unsafe & convenient, safe & Convenient, safe \\
\hline Posterior horn of the lateral meniscus & Inconvenient, unsafe & convenient, safe & Convenient, safe \\
\hline
\end{tabular}

\section{Outside-in technique}

The outside-in technique is most applicable for the anterior horn and the anterior part of the body of both the lateral and medial menisci [16]. To perform such a meniscus suture does not require special instruments and suture material. Thick needles for intravenous injections or spinal anesthesia are used. The stitching needles pass from the outside of the joint to inside in implementing the outside-in technique (Fig. 3). Next, a sewing thread passes through one needle, and a metal thread guide or a monofilament thread folded into a loop through the other. With the help of such a guide, the stitching thread is pulled outwards [17]. After all sutures have been applied, knots are formed on the joint capsule to avoid pressure of the sensitive branches of the $n$. saphenus in the ligature.

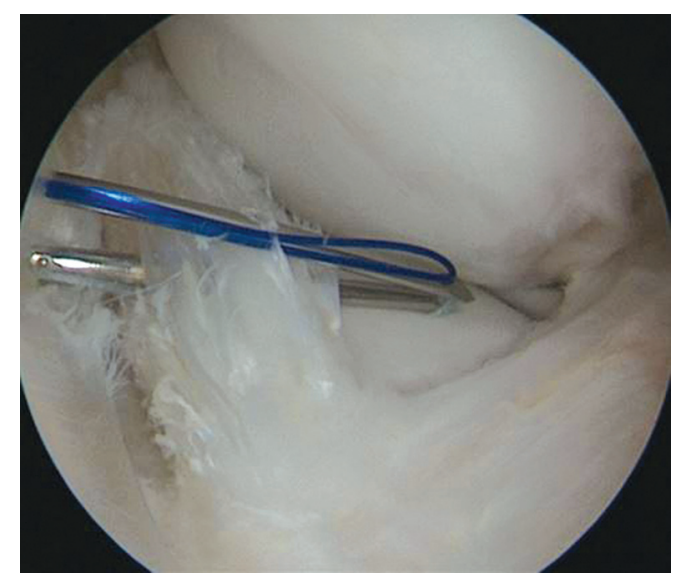

Fig. 3 Outside-in suture

The advantage of using this technique in the anterior part of the joint may be explained by a good view of the tear zone, a convenient "angle of attack" in relation to the tear line and sufficient space for manipulation of sutures and a guide thread, which minimizes the likelihood of iatrogenic trauma to the articular cartilage.

\section{Inside-out technique}

The most applicable technique for reconstruction of the middle and posterior parts of meniscus body is the inside-out suture by which the stitching needle passes from the joint to the outside (Fig. 4). To restore the middle and posterior parts of the meniscus body, it is possible to use the outside-in technique, but it requires from the surgeon much experience in meniscus suturing. There is a poorer view of the damaged zone in the middle part of the joint and the suture in the valgus position of the lower limb (for the medial meniscus) or in the "four" position (for the lateral meniscus), that is accompanied by changes in the orientation of the knee joint gap landmarks. Taking these features into account, the inside-out technique allows minimizing iatrogenic damage to the articular cartilage and neurovascular structures.

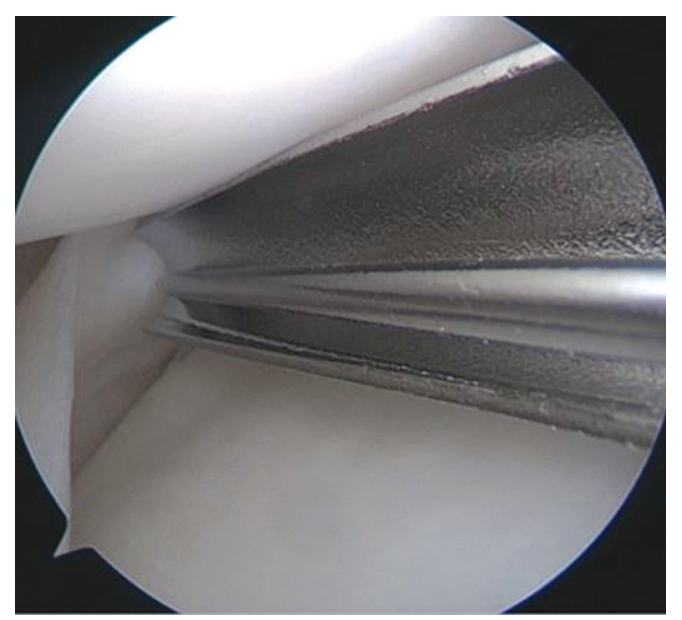

Fig. 4 Inside-out suture

For the inside-out meniscus suture, a stitching needle guide is used. The principle of the arrangement of the sutures is similar. It is important to use protective mirrors by passing the suturing needles to prevent stitching of tendons, muscles, and neurovascular structures [18, 19]. After passing all the suturing threads, the knee joint is bent to $90^{\circ}$ and the surgeon forms knots on the joint capsule [20]. This technique allows an adequate positioning of the damaged elements of the meniscus and minimizes the likelihood of damage to the sensitive branches of $\mathrm{n}$. saphenus.

To restore the posterior horn of the medial meniscus, it is necessary to release the deep branch of the medial collateral ligament [21, 22]. It improves the visibility of the damaged area of the posterior horn and the meniscocapsular junction, as well as minimizes iatrogenic damage to the articular cartilage.

To repair the tears of the medial meniscus ramp, the inside-out technique is also used. The difference is the need to perform an additional posterior medial approach to visualize the tear line, as well as the use of a retractor hook to protect the neurovascular structures from damage by the meniscus suturing [23]. 


\section{All-inside technique}

To restore the posterior horn of the meniscus, the most convenient and, most importantly, safe technique is "all inside". Reconstruction using this technique is performed with the help of special suturing devices that allow the suture to be made completely inside the joint without pulling the stitching threads outside (Fig. 5, 6) [24].

The use of other methods of the meniscus suture for reconstruction in the posterior part of the knee joint through the anterior ports cannot be considered safe. It is associated with a limited view of the posterior part of the joint, as well as with a high probability of damage to $\mathrm{v}$. saphena magna at suturing the posterior horn of the medial meniscus, n. peroneus communis by repair of the posterior parts of the lateral meniscus body and a. poplitea by reconstruction of the posterior horn of the lateral meniscus.

The all-inside meniscus suture is a fast, convenient and safe technique, but it requires special disposable instruments, thus significantly increasing the cost of such an operation.

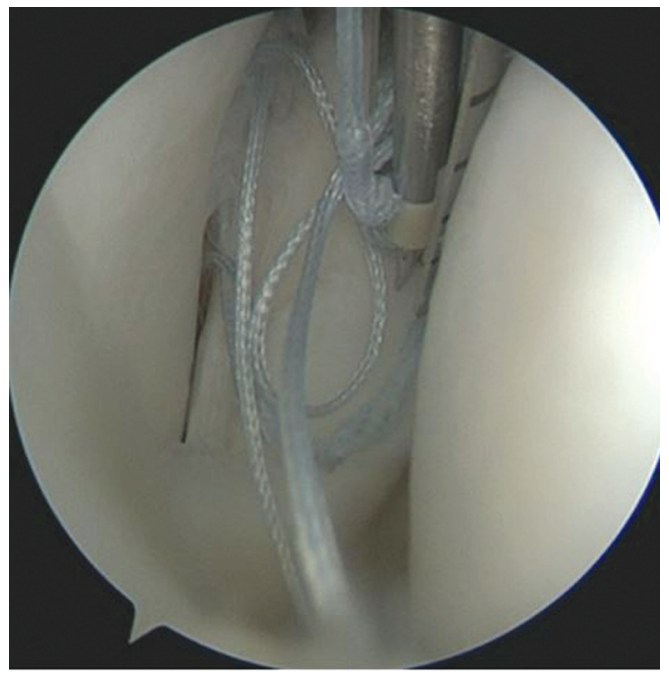

Fig. 5 All inside suture

\section{Transosseous suture for tear of the posterior root of the medial meniscus}

To reconstruct injuries to the root of the posterior horn of the medial meniscus, the technique of reinsertion the posterior root using cortical fixation on the anterior surface of the tibia has been described [25]. This technique allows anatomical fixation of the damaged segment, since a displacement of more than $3 \mathrm{~mm}$ may cause persistent pain and inconsistency of the suture. Also, there is frequently not just a tear of the meniscus tissue, but its complete separation from the insertion point, often along with a bone fragment [26].

Upon assessing the type of damage to the meniscal root according to the LaPrade classification [26], decortication is performed in the area where the meniscus root is planned to be re-attached. The tibial canal is formed with the help of a special guide. Next, the meniscal root is stitched inside the joint, and all the threads that fix the meniscus are immersed into the tibial canal with the help of a guide. The next step is fixation with a button on the anterior surface of the lower leg [27].

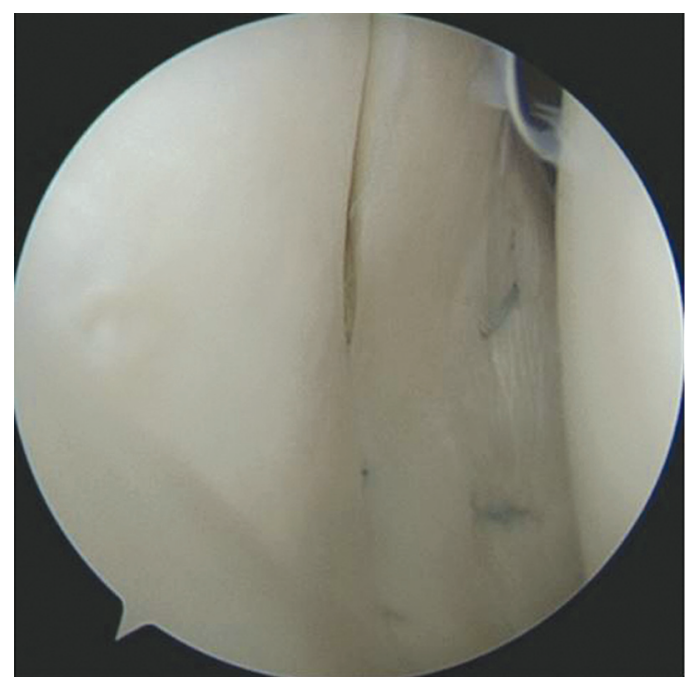

Fig. 6 Inside-out suture

\section{RESULTS}

In the postoperative period, all children underwent plaster immobilization of the knee joint for a period of 4-6 weeks (4 weeks in isolated lesion of the anterior meniscal horn, 6 weeks for other localizations) and exclusion of axial load for 6 weeks. In the early postoperative period ( $0-6$ weeks), exercises were performed to achieve full extension in the knee joint, isometric exercises for the quadriceps femoris muscle, and straight leg lift in all planes. After 6 weeks, a gradual restoration of the range of motion in the knee joint was initiated in the articulated orthosis and the axial load was allowed with a gradual achievement of full weight-bearing walking and restoration of a normal gait stereotype. From the 14th week, exercises were added to increase muscle strength and flexibility, while getting rid of the fear of uncertain support on the operated limb.

The consistency of the meniscus suture was assessed clinically and instrumentally at 6 months since the date of surgery (MRI). One year after the meniscus suturing, X-rays of the knee joint were taken to assess osteoarthritis. Pain was noted in 72 children (97.3\%) before surgery. After the meniscus suturing, pain persisted in 6 children $(8.1 \%)$. It should be noted that patients noted a change in the nature of pain and a decrease in its intensity. No block of the knee joint was observed in all children after the operation. Before surgery, it was detected in 34 children (46\%). Preservation of restricted movements in the knee joint after the meniscus suturing was noted in 5 children $(6.8 \%)$. Four of them had a massive tear of the meniscus (s), and ACL repair was performed at the second stage. Motion in the operated knee joint was restored fully in the remaining 69 children.

To compare the samples for qualitative characteristics, the McNemar test was used. We compared two groups of children who noted pain (group 1) and limitation of movement (group 2) before 
and after the meniscus suturing. Results obtained were: $\chi^{2}$ McNemara $19.600(\mathrm{p}<0.001) ; \chi^{2}$ McNemara with Yates' correction $18.906(\mathrm{p}<0.001) ; \chi^{2}$ McNemara with Edwards' correction $18.225(\mathrm{p}<0.001)$.

We faced complications in 5 children. One child had synovitis 4 months after the operation that resolved on its own by reduced physical activity. In 4 children, a decrease in sensitivity in the anteromedial region of the tibia was noted in the postoperative period. Two children had a complete recovery of sensitivity after 8 months from the moment of surgery, and partial recovery was observed in two other children (Table 4).

Complications

\begin{tabular}{|l|c|}
\hline \multicolumn{1}{|c|}{ Type of complication } & Number of children \\
\hline Synovitis & 1 \\
\hline $\begin{array}{l}\text { Decreased sensitivity along } \\
\text { the anteromedial surface } \\
\text { of the lower leg }\end{array}$ & 4 \\
\hline Total & 5 \\
\hline
\end{tabular}

One child had a meniscus tear due to a repeated injury 9 months after the meniscus suturing and the end of rehabilitation. Revision arthroscopy revealed areas where the suture was found to be inconsistent. In the rest of the patients, complaints and clinical data of the meniscus suture failure were not observed.

According to MRI data, patients were divided into several groups according to the following features: the presence or absence of a hyperintense signal, preservation of the meniscus shape, and the presence of synovitis. Synovitis according to MRI data in our study was noted in $3.5 \%$ of cases. Retention of the meniscus shape was noted in $91.5 \%$ of cases. In $8.5 \%$ of children, we met a discoid meniscus, which initially has an irregular shape. By the nature of the hypersignal, the patients were divided into 3 groups:

1) absence of any changes in the area of the restored menisci (20\%);

2) presence of a hyperintense signal that does not go out to the articular surface of the meniscus (52\%);
3) presence of a hyperintense signal going out to the articular surface of the meniscus $(28 \%)$.

It should be noted that the presence of a hyperintense signal in the absence of synovitis, altered meniscus shape and other MRI-symptoms of meniscal lesions (double posterior cruciate ligament symptom, ghost symptom, etc.) is not a criterion for meniscus tear in the absence of clinical manifestations. Reliable differentiation between meniscus tear and the presence of scar tissue in the zone of the restored meniscus is impossible. According to the literature, a hyperechoic signal in the meniscus tear zone may persist for up to 10 years from the moment of surgery and not disappear completely, provided that the damage zone is not macroscopically determined with control arthroscopy [28]. In this regard, in our work, we considered the absence of synovitis, the preservation of the contours of the reconstructed meniscus, and a decrease in the intensity of the hyperechoic signal in dynamics as criteria for a satisfactory MRI result, compared to MRI before surgery.

По данным контрольных рентгенограмм, выполненных через 1 год с момента оперативного лечения, ни у одного ребенка мы не выявили рентгенологических признаков артроза и иных изменений.

According to the control radiographs performed one year after the surgical treatment, we did not reveal any radiological signs of arthrosis or other changes in any child.

In 11 children, repeated arthroscopy was performed in connection with the delayed reconstruction of the ACL. At the same time, suture failure without clinical manifestations was detected in one child by repeated arthroscopy. The remaining 5 patients showed macroscopic signs of the ongoing meniscus repair. Four weeks after the meniscus suturing, the tear zone was covered with thin connective tissue, while the damaged part of the meniscus did not move by palpation with a probe. The repeated arthroscopy after more than 8 weeks showed that the tear zone was either not visually determined, or looked similar to the arthroscopic image described above.

\section{DISCUSSION}

There is strong evidence that complete or partial meniscectomy is a detrimental procedure in pediatric patients that causes the development of premature osteoarthritis [1]. V.B. Bogatov et al observed that the radiographic manifestations of osteoarthritis in adolescents are more pronounced than complaints and clinical data. The authors believe that resection of the floating fragments of the meniscus is advisable when there is a high probability of their infringement between the articular surfaces [29]. G. Lucas et al conducted a study aimed at evaluating the results of arthroscopic repair of isolated meniscal tears in children. Pre- and postoperative assessment of the results of the arthroscopic meniscus suturing was carried out according to the Tegner and Lisholm scales. Significant differences were revealed in the results of the questionnaire survey on both scales $(p=0.0003)[1]$.
Clinical and MRI-controlled good and excellent results were obtained in $70 \%$ of the patients [1]. In the study by A. Schmitt, complete restoration of the knee joint function was noted both according to the results of the questionnaire survey (IKDC, KOOS) and according to the MRI data in the postoperative period in 17 of 19 children after the meniscus suturing using the all-inside technique. The inconsistency of the suture was noted in two cases. There was also one case of limited flexion in the knee joint, which completely subsided after a course of physiotherapy [3]. P. Beaufils and N. Pujol reported that they used the all-inside technique to repair the posterior parts of the meniscus, and the outside-in one for the anterior parts. Also, the authors advise to suture first the damaged posterior meniscal parts, and then move anteriorly. An exception is a bucket-handle type of tear. According to the authors, it is not recommended 
to use the inside-out technique to restore the posterior horn of the meniscus, since this tactic is associated with the risk of neurological complications, especially in the medial region [16]. Another group of authors (J. Chahla et al.) believes that the inside-out technique is most applicable for the suture of the posterior horn and the body of the meniscus, the tear of the meniscus ramp and the restoration of the bucket-handle type. However, there is a possibility of injuring the popliteal artery and its branches, damage to the saphenous nerve and the common peroneal nerve, the development of flexion contracture and deep vein thrombosis [20].

According to the literature, the resulting changes lead to accelerated cartilage degeneration if the posterior root of the meniscus is injured, what is comparable to the changes observed after total meniscectomy [26]. S. Pache, G. Moatshe and R.F. Laprade believe that in young patients, even chronic and degenerative lesions of the posterior meniscus root are indications for surgical repair $[6,26]$. V.B. Bogatov et al in their study noted that the duration of the meniscus injury did not affect the outcome of treatment. The authors observed the restoration of the meniscus tissue in injuries that were more than 4 months old [29]. In turn, Mark E. Cinque et al performed repairs in 173 patients regardless of the tear zone ( 3 groups: red-red, red-white and white-white) and did not reveal any fundamental differences in the results of meniscus union in patients of these three groups [30].

\section{CONCLUSION}

In children, the potential for restoration of menisci after their reconstruction is noticeably higher than in adults. It is possible not only to restore the lesions in the white zone but also after a long time since the moment of injury. The choice of the meniscus suture technique used is determined by the location of the tear, taking into account possible complications (damage to the popliteal artery, great saphenous vein, saphenous nerve and common peroneal nerve) and the surgeon's skills. A combination of methods allows for the reconstruction of the damaged meniscus regardless of the location of the tear and the complexity of the injury.
The indications we have formulated for the use of various methods of meniscus stitching in children result in good treatment outcomes in the immediate postoperative period. At the moment, there are no long-term studies in the pediatric group of patients evaluating the role of the meniscus suture techniques in preventing the development of premature osteoarthritis. Good clinical results, absence of complaints and a return to the usual physical activity should be regarded as a positive short-term result of treatment that should be further investigated.

Conflict of interest The authors declare no conflicts of interest related to the publication of this study.

Ethical review The study was approved by the ethical board of the State Budgetary Healthcare Institution Morozovskaya Children's Clinical City Hospital (protocol No. 154 of 04/23/2020).

\section{REFERENCES}

1. Lucas G, Accadbled F., Violas P., Sales de Gauzy J., Knörr J. Isolated meniscal injuries in paediatric patients: outcomes after arthroscopic repair. Orthop. Traumatol. Surg. Res., 2015, vol. 101, no. 2, pp. 173-177. DOI: 10.1016/j.otsr.2014.12.006.

2. Sambatov B.G. Vnutrisustavnye miagkotkanye povrezhdeniia kolennogo sustava u detel i podrostkov. Artroskopicheskaia verifikatsiia diagnoza. Diss. kand. med. nauk [Intraarticular soft-tissue injuries of the knee in children and adolescents. Arthroscopic verification of the diagnosis. Cand. med. si. diss.]. M., 2010, 138 p. (in Russian)

3. Schmitt A., Batisse F., Bonnard C. Results with all-inside meniscal suture in pediatrics. Orthop. Traumatol. Surg. Res., 2015, vol. 102, no. 2, pp. 207211. DOI: 10.1016/j.otsr.2015.12.018.

4. Wilson P.L., Wyatt C.W., Romero J., Sabatino M.J., Ellis H.B. Incidence, Presentation and Treatment of Pediatric and Adolescent Meniscal Root Injuries. Orthop. J. Sports Med., 2018, vol. 6, no. 11, pp. 2325967118803888. DOI: 10.1177/2325967118803888.

5. Mosich G.M., Lieu V., Ebramzadeh E., Beck J.J. Operative treatment of isolated meniscus injuries in adolescent patients: A meta-analysis and review. Sports Health, 2018, vol. 10, no. 4, pp. 311-316. DOI: 10.1177/1941738118768201.

6. Pache S., Aman Z.S., Kennedy M., Nakama G.Y., Moatshe G., Ziegler C., LaPrade R.F. Meniscal Root Tears: Current Concepts Review. Arch. Bone Jt. Surg., 2018, vol. 6, no. 4, pp. 250-259.

7. Shimomura K., Hamamoto S., Hart D.A., Yoshikawa H., Nakamura N. Meniscal repair and regeneration: Current strategies and future perspectives. J. Clin. Orthop. Trauma, 2018, vol. 9, no. 3, pp. 247-253. DOI: 10.1016/j.jcot.2018.07.008.

8. Salikhov R.Z., Chekunov M.A., Plakseichuk Iu.A. Shov meniska. sravnenie rezultatov artroskopicheskikh tekhnik «vse vnutri» i «snaruzhi vnutr» [Meniscus suture. Comparison of the results of arthroscopic techniques "everything inside" and "from outside to inside"]. Prakticheskaia Meditsina, 2016, no. 4 (96), pp. 143-145. (in Russian)

9. McDermott I.D., Amis A.A. The consequences of meniscectomy. J. Bone Joint Surg. Br., 2006, vol. 88, no. 12, pp. 1549-1556. DOI: 10.1302/030 1-620X.88B12.18140.

10. Bellisari G., Samora W., Klingele K. Meniscus tears in children. Sports Med. Arthrosc. Rev., 2011, vol. 19, no. 1, pp. 50-55. DOI: 10.1097/ JSA.0b013e318204d01a.

11. Manzione M., Pizzutillo P.D., Peoples A.B., Schweizer P.A. Meniscectomy in children: a long-term follow-up study. Am. J. Sports Med., 1983, vol. 11, no. 3, pp. 111-115. DOI: 10.1177/036354658301100301.

12. Pavlova D.D., Petrova M.A., Saburova K.A. Shov meniska kolennogo sustava u detei [The knee meniscus suture in children]. Turnerovskie Chteniia: Sbornik statei Ezhegodnoi Nauchno-prakticheskaia Konferentsii po aktualnym voprosam travmatologii i ortopedii detskogo vozrasta [Proceedings of the Annual Scientific-Practical Conference on the Current-Interest Problems of Traumatology and Orthopaedics of Childhood: Turner Readings]. SPb., 2019, pp. 234-238. (in Russian)

13. Sadykov R.Sh., Bogatov V.B., Shormanov A.M., Radzhabov A.M. Osobennosti gistomorfologicheskogo stroeniia meniskov kolennogo sustava u detei [Peculiar characteristics of the knee menisci histomorphological structure in children]. Politravma, 2013, no. 2, pp. 67-72. (in Russian)

14. Korolev A.V., Riazantsev M.S., Magnitskaia N.E., Afanasev A.P., Ilin D.O., Frolov A.V. Otdalennye rezultaty sshivaniia meniskov pri artroskopicheskoi plastike perednei krestoobraznoi sviazki [Long-term results of menisci suturing when arthroscopic plasty of the anterior cruciate ligament]. Travmatologiia i Ortopediia Rossii, 2016, vol. 22, no. 3, pp. 44-53. (in Russian)

15. Pavlova D.D., Sharkov S.M., Petrova M.A., Krainova E.M. Opredelenie taktiki lecheniia povrezhdenii meniskov u detei na osnove klassifikatsii [Defining the tactics of treating the menisci injuries in children based on classifications]. Detskaia Khirurgiia, 2020, vol. 24, no. 3, pp. 194-197. (in Russian) 
16. Beaufils P., Pujol N. Meniscal repair: Technique. Orthop. Traumatol. Surg. Res., 2018, vol. 104, no. 1S, pp. S137-S145. DOI: 10.1016/j. otsr.2017.04.016

17. Steiner S.R.H., Feeley S.M., Ruland J.R., Diduch D.R. Outside-in Repair Technique for a Complete Radial Tear of the Lateral Meniscus. Arthrosc. Tech., 2018, vol. 7, no. 3, pp. e285-e288. doi.10.1016/j.eats.2017.09.006.

18. Hetsroni I., Mann G., Marino G., Ohana N. Inside-out repair of extensive meniscal tears using posteromedial and posterolateral neurovascular protective windows. Arthrosc. Tech., 2021, vol. 10, no. 1, pp. e131-e138. DOI: 10.1016/j.eats.2020.09.019.

19. Youn G.M., Van Gogh A.M.R., Mirvish A.B., Chakrabarti M.O., McGahan P.J., Chen J.L. Inside-out bucket-handle meniscus repair with a singlehanded self-advancing zone-specific meniscus repair device. Arthrosc. Tech., 2020, vol. 9, no. 1, pp. e117-e121. DOI: 10.1016/j.eats.2019.09.007.

20. Chahla J., Serra Cruz R., Cram T.R., Dean C.S., LaPrade R.F. Inside-Out Meniscal Repair: Medial and Lateral Approach. Arthrosc. Tech., 2016, vol. 5, no. 1, pp. e163-e168. DOI: 10.1016/j.eats.2015.10.017.

21. Sherman B., Harrah T., Schlechter J.A. Reluxation of the medial collateral ligament to facilitate pediatric meniscal surgery. Arthrosc. Tech., 2019, vol. 8, no. 11, pp. e1345-e1351. DOI: 10.1016/j.eats.2019.07.010.

22. Moran T.E., Demers A., Awowale J.T., Werner B.C., Miller M.D. The outside-in, percutaneous release of the medial collateral ligament for knee arthroscopy. Arthrosc. Tech., 2020, vol. 9, no. 3, pp. e393-e397. DOI: 10.1016/j.eats.2019.11.008.

23. DePhillipo N.N., Cinque M.E., Kennedy N.I., Chahla J., Geeslin A.G., Moatshe G., Engebretsen L., LaPrade R.F. Inside-Out Repair of Meniscal Ramp Lesions. Arthrosc. Tech., 2017, vol. 6, no. 4, pp. e1315-e1320. DOI: 10.1016/j.eats.2017.05.011.

24. Kotsovolos E.S., Hantes M.E., Mastrokalos D.S., Lorbach O., Paessler H.H. Results of all-inside meniscal repair with the FasT-Fix meniscal repair system. Arthroscopy, 2006, vol. 22, no. 1, pp. 3-9. DOI: 10.1016/j.arthro.2005.10.017.

25. Drynan D., Betsch M., Aljilani W., Whelan D.B. Arthroscopic medial meniscal posterior root repair with transtibial luggage-tag and horizontal mattress sutures. Arthrosc. Tech., 2021, vol. 10, no. 1, pp. e21-e27. DOI: 10.1016/j.eats.2020.09.004.

26. Moatshe G., Chahla J., Slette E., Engebretsen L., Laprade R.F. Posterior meniscal root injuries. Acta Orthop., 2016 , vol. 87, no. 5, pp. 452-458. DOI: $10.1080 / 17453674.2016 .1202945$.

27. DePhillipo N.N., Kennedy M.I., Chahla J., LaPrade R.F. Type II Medial Meniscus Root Repair With Peripheral Release for Addressing Meniscal Extrusion. Arthrosc. Tech., 2019, vol. 8, no. 9, pp. e941-e946. DOI: 10.1016/j.eats.2019.05.001.

28. Pujol N., Tardy N., Boisrenoult Ph., Beaufils Ph. Magnetic Resonance Imaging is not suitable for interpretation of meniscal status ten years after arthroscopic repair. Int. Orthop., 2013, vol. 37, no. 12, pp. 2371-2376. DOI: 10.1007/s00264-013-2039-6.

29. Bogatov V.B., Bakhteeva N.Kh., Mitrofanov V.A. Otdalennye rezultaty artroskopicheskikh vmeshatelstv pri travmakh kolennogo sustava u detei [Long-term results of arthroscopic interventions for the knee injuries in children]. Travmatologiia i Ortopediia Rossii, 2010, vol. 57, no. 3, pp. 5560. (in Russian)

30. Cinque M.E., DePhillipo N.N., Moatshe G., Chahla J., Kennedy M.I., Dornan G.J., LaPrade R.F. Clinical Outcomes of Inside-out Meniscal Repair According to Anatomic Zone of the Meniscal Tear. Orthop. J. Sports Med.. 2019, vol. 7, no. 7, pp. 2325967119860806. DOI: $10.1177 / 2325967119860806$.

Received: 04.02.2021

\section{Information about the authors:}

1. Daria D. Pavlova, M.D.,

Morozov Children's Clinical Hospital, Moscow, Russian Federation,

ORCID 0000-0002-2155-2694, eLibrary SPIN 9416-5961,

Email: pavlova-med@mail.ru

2. Sergey M. Sharkov, M.D., Ph.D.,

Morozov Children's Clinical Hospital, Moscow, Russian Federation,

Sechenov First Moscow State Medical University, Moscow, Russian Federation,

ORCID 0000-0001-8579-2227, eLibrary SPIN 4637-6392

3. Mikhail A. Petrov, M.D., Ph.D.,

Pirogov Russian National Research Medical University, Moscow, Russian Federation,

ORCID 0000-0003-4383-2707,

Email:m.petrov@me.com 